and skill: The sharp crack of a broken crank, the dull thud of a shattered connecting rod-in short, any of those obscure noises which signalize the approaching disability of a great machine, and any of those accidents which interfere with smooth running, may often, if readily discovered, save largely both of lives and property.

A veteran engineer says that two years ago a slight difference in the aggregate quality of the tones which came to his ear caused him to stop his train and look over the engine. "I found the trouble," said he, " to be due to the loosening nuts of two cylinder heads, which had been put in place without the usual precautions to prevent their working off. Had they done so, I would have carried in a crippled train, and changed the whole business of the road for some hours." "Then you consider quick and reliable hearing of importance to the locomotive engineer?" "No man," he replied, "has a right on an engine who has not all of his senses in perfect running order. The very feel of an engine when she is running is of the highest importance. A moment of rashness on the part of the engineer might in some instances lose him his engine."

The driver of a Hudson River Railroad locomotive said: "I was affected with deafness but once. There was some heavy artillery firing in Yonkers which lasted about ten minutes; my ears were very sensitive, made so, I think, through the habit of careful listening, and the moment I started up I felt there was something wrong about my hearing. At the end of ten days I put myself under the care of a physician. He found the trouble a considerable distance inside, and told me the concussion of the air bad affected me. I was all right in ten days."

An instance in point is given in London Lancet, December 24, $188 \mathrm{I}$, in which an accident occurred in Canonbury, England. Three trains collided in a tunnel, in which the signalman stated he gave a word of caution to the passing driver, which the latter asserts he did not hear. A similar accident happened in France, in October, r 880 , fortunately without loss of life, but with a very great impediment to travel. It has been well expressed by Moos that, for the safety of the traveling public and for the prevention of accidents on railroads, not only a certain minimum of hearing is to be required, but both sight and hearing should be perfect, since sometimes reliance must be placed in one, sometimes in the other, and often in both combined. By such requirements only can danger and accident be reduced to a minimum.

\section{CARBONATE OF TITANIUM.}

BY A. B. LYONS, M.D., DETROIT.

Read before the Detroit Academy of Medicine, November 18, 1884 .

\section{Gentlemen of the Academy :}

The use of a class of remedies whose composition is either wholly the secret of the manufacturer, or else is deliberately misrepresented in the statements purporting to give an account of their composition, seems to be gaining ground among reputable physicians. I cannot but regard this as a misfortune to the profession. A few years ago there were few educated physicians who would attempt to defend the use of nostrums and secret remedies. Now I meet often with men who hold a high position in the medical profession who openly maintain that the physician ought not to be restricted in any way in the choice of his remedies. They take apparently high philanthropic ground, and say that we have no right to deprive our patients of the benefit they might obtain from the use of a secret remedy, merely on account of our ignorance of its constituents. 'They argue, further, that our knowledge of therapeutics is all or nearly all empirical; when we prescribe opium or potassium bromide, or any other article of the recognized materia medica, we do so merely because clinical experience has shown that patients in conditions similar to those existing in the case on hand have been benefited-not because we know how the remedy acts. Why, then, should we refuse to prescribe St. Jacob's Oil or Swaim's Panacea, if we have evidence that these nostrums, better than anything described in the pharmacopœia, will ameliorate our patient's condition? The reply has always been this: Manufacturers of nostrums are not in possession of any remedies unknown to the profession; their claims are based on falsehood. and if we are unable to obtain from known remedies the results we see produced by the combinations offered by charlatans, it is simply from our own ignorance of the subjects to which we are supposed to have given the closest study. To prescribe a quack medicine is therefore practically to admit that our own pretensions have been hollow and false.

For the pride of our profession, therefore, we should hold strictly to the requirements of our ethical code. But it is not necessary to place it on the ground of pride simply.

Notoriously the stateruents of charlatans are, to express it miidly, untrustworthy. In studying the effect of a quack medicine, too, we have to bear in mind the fact that the exaggerated statements which generally accompany the remedy have a powerful moral influence. Influences of this kind ought to emanate from the physician himself, and they must of necessity complicate all studies of the action of remedies; in the case of patent medicines they are not only a disturbing element, but one which must antagonize the personal influence of the physician. It is moreover so easy in most cases to penetrate the disguise under which well-known remedies masquerade as patent medicines, that the physician is inexcusable who prescribes the nostrum in ignorance of its real composition-and, certainly, equally inexcusable if, with such knowledge, he continues to prescribe it.

So long as the question relates merely to patent medicines and quack nostrums, the profession is as yet pretty well united-if not in practice at least in theory.

But within the last few years a new class of secret remedies has made its appearance and the old battle has to be fought over again, but with the foe now conspicuously displaying a flag of truce. 
Pharmacy, we are told, is making such rapid strides in our age that the pharmacopoia is quite unable to keep up with the march of progress. Hence enterprising manufacturers come to the rescue, seizing upon each valuable discovery in therapentics and embodying it in the form of a proprietary preparation. Then, too, remedies must be offered in this civilized age in a palatable form, and a preparation of any well-known drug, if only it possesses this recommendation, is hailed with satisfaction by physicians of the old school of practice who observe that their patients are drifting over to their homœopathic rival-because they do not have to take such nasty medicines. The large body of professional pharmacists who have endeavored to serve our profession by devising palatable and elegant preparations which should not be the property of any individual, but freely given for the good of humanity, find themselves put one side by the "enterprising" egoist who advertises iodia, or viburnum compound, or celerina or caulocoriaand a thousand other proprietary articles of which the formula is withheld. The properties and uses of preparations of this class are generally stated in language intelligible enough to the laity, and often the certificates of a score of distinguished medical professors are appended. You see no real difference between them and ordinary patent medicines-even in the prices, and yet the manufacturers distinctly state "For physician's prescriptions only" - it must be all right.

It is not surprising that physicians are perplexed, especially when all the medical journals, many of them conducted by men having an honored place in the profession, publish the advertisements of these secret remedies. To me it seems not difficult to decide where the discriminating line should be drawn. We cannot object to any preparation of acknowledged merit of which the formula is honestly published. When the formula is withheld we should refuse our sanction, especially when the preparation is offered under any fanciful name, such as papine, hydroleine, etc. By consistently adhering to such a course we should be very soon rid of the nuisance we all alike complain of, for manufacturers would find it suddenly to their interest to make common cause with scientific pharmacists, to the ultimate advantage of all parties. Any other course opens the way inevitably to frauds without number-and already we find instances not a few in which physicians have cut a sorry figure as dupes of the manufacturing charlatan. A short time since, a brazen attempt was made to impose upon the profession, as a great discovery, a medicinal preparation called " cohothedræ compound" (disregard of grammatical form is one distinguishing peculiarity of these innovators in pharmacy), a cure for typhoid fever, an analysis of the preparation by a distinguished chemist being offered in lieu of a formula. It makes little difference how often or how completely these frauds are exposed, the same medical journal which in its editorial columns may call attention, possibly once, to the exposure, continues week after week or month after month to publish advertisements of the preparation, often with a long list of references to eminent physicians. It seems to me that the only way we can protect ourselves against imposition is to put quackery in pharmacy on the same level as quackery in medicine, judge it by the same laws, and guard ourselves against it by adhering to the same ethical regulations. If a practitioner of medicine claims to have some remedy or gift of healing peculiar to himself, we withdraw from him our fellowship-rather let me say he places himself of necessity outside the pale of professional fellowship. The same principle applies equally to the man who claims to have a pharmaceutical secret. We are sure that such a man has not the interests of pharmacy at heart ; it is unreasonable to suppose that his claim has any better foundation in fact than that of the medical charlatan. As one reasonably familiar with pharmaceutical products, I may go further than this and say that as a matter of fact these much advertised proprietary medicines do not evince either inventive genius or any high order of pharmaceutical skill.

After all this preface I come to the immediate subject of this paper. The September number of the Medical World of Philadelphia, contains the following notice of a new emmenagogue, which we quote verbatim et literatim:

" The pill used by the French women to produce barrenness I have found a valuable emmenagogue. Each pill contains two grains each of aloes and carbonate of titanium. They have never failed to bring on the menstrual discharge at the next epoch. Stoppage produced by cold is restored by this preparation in forty-eight hours. It is a most powerful direct stimulant to the sexual organs. I have no doubt that it would produce barrenness if persevered in. A married woman using the pill does not become preg. nant.

"My usual formula is as follows:

" $\mathbf{R}$ Pulv. aloes (soc.) ........... Carb. titan............. āā $3 \mathrm{i}$

Fjant pilulæ No. xxx. Sig. One pill three times daily.

"No particular nicety need be paid in regard to dose; from one to three pills may be taken ter die. They should be commenced from one week to ten days before the expected menstrual period. I have employed them in many cases of amenorrhoea, both in retention and suppression, and almost invariably with the utmost gratifying results. So certain are they to restore the uterine sccretion when suppression does not depend upon organic disease that I almost regard them as a specific. Their action is peculiar; they seem to possess the power of restoring the secretion when suppressed, and of promoting it when deficient. This pill is, in fact, a female regulator. When the obstruction is from cold, these pills, with warm pediluvia, are sufficient. They operate kindly and without excitement ; the patient hardly knows she is restored."

The communication is from Dr. M. M. Griffith, of Du Bois, $\mathrm{Pa}$., who a few years ago brought to the notice of the medical profession crude petroleum mass as a therapeutic agent.

There is no intimation in the communication that the carbonate of titanium is not a perfectly well- 
known compound, and possibly it may be that the name, at least, was not an unfamiliar one in Pennsylvania. Elsewhere in the United States, however, it had a strange sound. In the Medical World for October it was stated editorially that the carbonate of titanium was a rare drug, expensive and hard to obtain, and that it was not to be had in any of the large cities, but that a supply had been ordered from abroad, while a later notice stated that one firm in Philadelphia was prepared to furnish the article, at the moderate price of $5 \circ$ cents per ounce.

I have left it to members of the Academy to form their own opinions in regard to the value of a drug which will inevicably produce barrenness in a married woman ; but I cannot forbear quoting a few sentences from the editorial alluded to as indicating the drift of popular sentiment inside as well as outside of the profession.

"The article of Dr. Griffith in the September World has created a widespread interest in carbonate of titanium. We have received numerous inquiries concerning it. Telegraphic orders were received for it in New York from Boston, Louisvil!e, and all parts of the country. ** We invite a report of further experience with this drug, hoping that the gratifying results of Dr. Griffith zeill be verified. Menstrual irregularities are becoming more and more prevalent, [among married women?], and any drug promising so much as carbonate of titanium should be fully tested."

Whether the six to eighteen grains a day of aloes prescribed would not of itself be sufficient to induce barrenness in a delicate female, I leave also to my hearers to judge.

My own attention was especially caught by the evident incongruity in the name itself. Carbonate of titanium to the ear of the chemist sounds about as plausible as pterygium of the iris to an oculist. I had a curiosity to see a chemical compound realizing such a singular freak of chemical affinity. Accordingly I awaited with some impatience the arrival of a supply of the drug. I have with me a sample of the article received with the written, not printed, label "carbonate of titanium." Any one familiar with drugs would guess at once that it was what formerly was known as iron sub-carbonate, but that compound, which is in reality ferric oxide, is tasteless, while this has a disagreeable ferruginous and bitter taste.

I found that a portion only of the substance dissolved in water, and this portion gave reactions for iron (ferrous) and for sulphuric acid. It consisted in fact, almost entirely of ferrous sulphate. After most of this salt was washed out, however, water continued to dissolve slowly something which had a bitter taste, and communicated to the water a strong orange tinge. The solution contained a vegetable alkaloid which proved to be sanguinarine, quantity too small to be easily estimated.

The residue insoluble in water was treated with hydrochloric acid, which dissolved it slowly, without effervescence, leaving only a few fragments of vegetable tissue, which were referred to the blood-root otherwise shown to be probably present, but were not positively identified. The solution consisted almost wholly of ferric chloride, showing that the insoluble substance had been in fact sub-carbonate of iron. Besides these principal constituents, the powder contained traces of calcium, potassium, sodium, silica, and titanic acid.

Quantitative analysis showed the composition of the powder to be approximately as follows:

Ferrous sulphate (cryst.). . . . 54.8

Ferric oxide ........... 40.5

Lime salts )

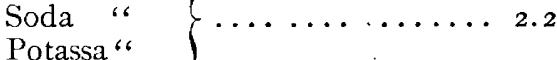

Titanic acid and Silica.......... r.o

Organic matter (blood-root) and

loss................... 5

100.0

Practically, therefore, it consists of a mixture of nearly equal parts of sub-carbonate of iron and sulphate of iron, partially exsiccated, with addition of an insignificant quantity of blood-root, and the " new" emmenagogue proves to be the old familiar combination of aloes and iron.

I am entirely ignorant of the source from which this powder was originally procured. It was sent to me by a leading wholesale drug house in New York, who undoubtedly were dealing in good faith. Possibly it has really come from France under the name it now bears, and that name may have been given it without any intent to deceive. But chemical names have a definite invariable significance, and when a substance is labelled titanium carbonate, you have a right to expect at least that it will prove to be a car. bonate, and it is not unreasonable to feel some disappointment if titanium is so nearly absent that the blowpipe fails to show its presence. Yet it is to precisely such impositions as these that the medical profession lays itself liable when it pleads ignorance as an excuse for accepting the dicta of men who confessedly tell only a part of the truth. I do not know who is the responsible person in the present instance, but I resent, as a gross insult to the profession, the attempt, if such has been deliberately made, to pass off a mixture of well-known medicinal agents as a new remedy of extraordinary power, and that under a name so impudently false.

Since writing the above I have come across some additional items of information in regard to titanium carbonate. In the Druggist's Circular for October, I 884, we find S. W. D., of Mansfield, Pa., asking for a short account of the physiological action of carbonate of titanium. Observe that he does not inquire what it is or where it is to be procured, and note that he writes from a town or village not a hundred miles from Du Bois.

His query is promptly answered in the November number of the Circular-not by the editor, but by M. Milton, M.D., who writes from Du Bois, Pa., a townsman, therefore, it seems of Dr. M. Milton Griffith, and possibly, we may conjecture from similarity in name, a near relative.

From the reply we quote a few sentences, which leave no doubt about the character of the preparation, and settle conclusively the question what atti- 
tude the profession must take toward the newly discovered "emmenagogue."

First, we are told that "titanium is found in several mineral species, in combination with magnetic iron ores. It is of a red color, and resembles copper. It is used to some extent in the arts." (Neither of the two latter statements, by the way, is true.) "Carbonate of titanium is made by double decomposition of sulphate of titanium and carbonate of sodium. It is a reddish-browi powder of a disagreeable, bitterish taste, partly soluble in water." This volunteered information is highly interesting, especially to one who has keenness enough to read between the lines. Its cunning blending of truth with fiction shows consummate genius in the perpetrator of this most daring fraud. Now listen. Properties: "It is tonic, alterative, and emmenagogue. It has produced abortion in many instances, and is commonly resorted to for that purpose by reckless women, and advised by still more reckless physicians. It seems to act without producing the very alarming symptoms usually attending such cases. It has the reputation of preventing married women from becoming preguant, by its use in combination with aloes; it has surely done it in a number of cases that have come under my observation. It is generally used in domestic practice, in the form of a saturated tincture with whisky." How singular that a compound of the rare element, titanium, should first come into use as a domestic remedy, and that in the rural districts in Pennsylvania! "My attention was first called to it by its domestic use for purposes not altogether legitimate. It is a valuable remedy, and is worthy of further consideration."

Emmenagogue forsooth! Was there ever a more unblushing advertisement of a foeticide? It matters not that the drug is innocent of the active properties attributed to it ; it will be bought for illegitimate purposes, and no other. In view of this fact, I am sure that no member of the Academy will regard the carbonate of titanium with any favor or indulgence, or will fail, indeed, on all fitting occasions to denounce it as an attempt to drag the profession into association with a class of criminals whose practices we utterly abhor and condemn.

\section{A CASE ILLUSTRATING THE APPLICABILITY OF MURIATE OF COCAINE IN NASAL SURGERY.}

\author{
BY JEFFERSON BETTMAN, M.D., CHICAGO.
}

(Read before the Chicago Medical Society, Nov. II 1884.)

The introduction of muriate of cocaine will no doubt create an era in ophthalmic surgery, the glowing tributes it has already received in Europe and in the East render irrefutable its qualities as a most efficient and innocuous local anæsthetic. Both Knapp and Gruening, of New York, have already tested its action on the nasal mucous membrane, and the re- sults attained thereby fully equal those in anæsthetizing the eye. Due to the extreme scarcity of the drug in Chicago, it is only at a late hour that I have been able to obtain a small quantity and to apply it in practice. Although my actual experience, so far, has been limited to the case subjoined, the striking results attained are sufficient to fulfill my most sanguine expectations and to regard it as a most valuable adjunct in nasal surgery.

Dr. K., a physician of this city, has been under treatment for some time, suffering from asthma nervosum. Observations render it beyond doubt, that the asthma is purely reflex, induced by great hypertrophy of both inferior turbinated bones. Barring occasional obstructions to the free nasal respiration, but little discomfort is experienced during the day. A recumbent position, the warmth generated by the bedding are sufficient to produce reflexly a sudden turgescence of the turbinated bones, blocking up of the respiratory fissure, a serous discharge, and to finish the clinical picture, a culminating, violent attack of asthma. The hyperæsthesia of the nares is truiy extraordinary, the simple introduction of the speculum is painful. The doctor has to exert all his self-control to permit the mere application of the probe to the parts. Endeavors had heretofore been directed to reducing the cavernous tissue by means of the galvano-cautery. The extreme sensibility would not permit of a thorough and prolonged application of the cautery, sufficient to act upon the deeper lying structures, so the results obtained were but partially successful. Last Saturday the doctor called at my office and we resolved to apply the muriate of cocaine prior to cauterization. Gruening, according to his report, instilled the solution into the inferior meatus, the patient's head being placed accordingly.

The small quantity of the solution at hand, compelled me to adopt another method, which impressed me as being more expedient, and at the present not unworthy of consideration, as far more economical. A pledget of cotton, sufficient in bulk to occlude the inferior meatus, was soaked with 15 drops of a 4 per cent. solution of cocaine and placed in the left nostril, between the septum and enlarged turbinated bone. At intervals of five minutes, two or three drops were instilled upon the cotton in situ. At the lapse of ten minutes, the left narium was so anæsthetized as not to perceive the touch of the probe. However, as a precautionary measure, I only removed the cotton at the expiration of a quarter of an hour. The anæsthesia of the parts was now so profound, that the gentleman could hardly give credence to my assurances that I had thoroughly and vigorously probed the parts. In marked contrast was the undiminished sensibility of the right nostril ; the introduction of the probe compelling him to cry out lustily. Previous cauterization had been made with the flat, surface electrodes, our aim, however, being to destroy the underlying cavernous tissue, we resolved to use a sharp, cutting point which had been made according to my design by Dr. McIntosh, of this city. The plates of the battery (a large Bruns battery

1 Medical Record, November $1,1884$. 